\title{
Comparison of Brachiobasilic Transposition Arteriovenous Fistula Outcomes among Diabetic and Non-diabetic Patients: A Case Controlled Study
}

\author{
Zia Ur Rehman, Waryam Muhammad Saleh and Anum Sadruddin Pidani \\ Department of Surgery, The Aga Khan University Hospital, Karachi, Pakistan
}

\begin{abstract}
Diabetes is considered a risk factor for arteriovenous fistula failure and increased perioperative complications; but this view is not proven for patients undergoing brachiobasilic transposition arteriovenous fistula (BBT-AVF). Fifty-one (68.9\%) diabetic and 23 (31.08\%) non-diabetic patients undergoing single-stage BBT-AVF were compared in terms of perioperative complications, access maturation and patency rates at The Aga Khan University Hospital from between January 2016 to December 2017. Diabetics were elder and more obese. The perioperative complications 19 (37.2\%) vs. 8 (34.7\%), and access maturation rates were compared (93.2\% vs. 95.5\%) between the two groups. At 6 months, access patency in diabetics was lower compared to non-diabetics (64.7\% vs. $87.0 \%)$. Similar trend was noted at 12 and 24 months in both groups.

This study showed that the diabetic and non-diabetic were comparable in terms of perioperative complications and maturation rate. However, short term patency rate was lower in diabetics compared to non-diabetics.
\end{abstract}

Key Words: Brachiobasilic AVF, Complications, Diabetes mellitus, Patency.

How to cite this article: Rehman ZU, Saleh WM, Pidani AS. Comparison of Brachiobasilic Transposition Arteriovenous Fistula Outcomes among Diabetic and Non-diabetic Patients: A Case Controlled Study. J Coll Physicians Surg Pak 2021; 31(08):1001-1003.

In literature, there is wide variations of primary patency for brachiobasilic transposition arteriovenous fistula (BBT-AVF). Same is true for the perioperative complications. This wide variability may be due to heterogeneous patient population in the published studies, including both diabetic and non-diabetic patients. Patients with long standing diabetes develop medial calcification in their arteries, which prevents its dilatation and increase flow within the fistula. ${ }^{1}$ Distal brachial artery along with forearm arteries may be involved in extensive atherosclerosis, which is inflow site for most of elbow AVFs. This can be associated with delayed AVF maturation or its early failure.

Diabetes is also a negative predictor of venous remodelling. ${ }^{2}$ Endothelial dysfunction in diabetics causes less nitric oxide production, increased platelet aggregation and pro-coagulant state, which can delay maturation or poor patency of $\mathrm{AVF}^{3}$. Diabetics are immune-compromised and more prone to surgical site infection. ${ }^{1}$

Correspondence to: Dr. Zia-Ur-Rehman, Section of Vascular Surgery, Department of Surgery, The Aga Khan University Hospital, Karachi, Pakistan

E-mail: ziaur.rehman@aku.edu

Received: December 03, 2019; Revised: January 30, 2020;

Accepted: February 18, 2020

DOI: https://doi.org/10.29271/jcpsp.2021.08.1001
Based on these factors, the authors hypothesised that patency of AVF may be lower and the incidence of complications may be higher in diabetic compared to non-diabetic patients undergoing BBT-AVF. There is enough data to support these impressions for forearm fistulas; but limited evidence for the BBT-AVF.

The objective of the study was to compare the perioperative complications, access maturation, and patency rate in diabetic and non-diabetic patients' undergoing BBT-AVF.

This observational study was conducted at The Aga Khan University Hospital, Karachi (Pakistan) from January 2016 to December 2017; and included all adult patients who had undergonesingle-stage BBT-AVF. The cohort was followed for at least one year. Patients undergone two-stage BBT-AVFs were excluded from the study.

After obtaining exemption from the Institutional Ethical Review Board (2018-0663-727), medical records of the patients, who underwent BBT-AVF, were retrieved from the electronic database using ICD coding. Data of patients' age, gender, body mass index, primary renal pathology leading to end-stage renal disease, comorbidities, previous vascular access if any, preoperative size of basilic vein, anesthesia used for surgery, total operative time, early or late complications, time for first needle puncture, primary patency, first re-intervention time, total interval between the initial procedure and until the fistula is lost and causes of fistula failure, were recorded. The complications include arm oedema, wound infection, graft thrombosis, stenosis, steal syndrome, haematoma / bleeding and re-interventions. 
Table I: Patient's characteristics and outcomes.

\begin{tabular}{|c|c|c|c|}
\hline Variable & Diabetic $(n=51)$ & Non-diabetic $(n=23)$ & p-value \\
\hline Age (years) & $60.27 \pm 8.96$ & $43.78 \pm 17.41$ & $<0.001$ \\
\hline BMI $\left(\mathrm{kg} / \mathrm{m}^{2}\right)$ & $28.32 \pm 7.18$ & $23.59 \pm 4.51$ & 0.005 \\
\hline Female gender & $39(76.47 \%)$ & $10(43.48 \%)$ & 0.005 \\
\hline HTN & $49(96.08 \%)$ & $19(82.61 \%)$ & 0.071 \\
\hline IHD & $21(41.18 \%)$ & $4(17.39 \%)$ & 0.063 \\
\hline CVA & $5(9.80 \%)$ & $3(13.04 \%)$ & 0.698 \\
\hline Previous hemodialysis access & $26(50.98 \%)$ & $11(47.83 \%)$ & 0.802 \\
\hline Duration of hemodialysis (years) & Median: $0.25(0-8)$ & Median: $0.5(0-20)$ & 0.288 \\
\hline Preoperative basilic vein size $(\mathrm{mm})$ & $4.05 \pm 0.73$ & $3.44 \pm 0.64$ & 0.130 \\
\hline $\begin{array}{l}\text { Anaesthesia: } \\
\text { General Anaesthesia } \\
\text { Local Anaesthesia } \\
\text { Regional Anaesthesia }\end{array}$ & $\begin{array}{c}36(70.6 \%) \\
1(2.0 \%) \\
14(27.5 \%)\end{array}$ & $\begin{array}{c}19(82.6 \%) \\
0(0.0 \%) \\
4(17.4 \%)\end{array}$ & 0.492 \\
\hline Overall complication rate & $19(37.3 \%)$ & $8(34.8 \%)$ & 0.838 \\
\hline $\begin{array}{l}\text { Complications type: } \\
\text { Edema } \\
\text { Hematoma/bleeding } \\
\text { Steal syndrome } \\
\text { Vascular thrombosis } \\
\text { Stenosis } \\
\text { Wound infection }\end{array}$ & $\begin{array}{c}5(9.8 \%) \\
2(3.9 \%) \\
10(19.6 \%) \\
1(2.0 \%) \\
1(2.0 \%) \\
0(0.0 \%)\end{array}$ & $\begin{array}{c}2(8.70 \%) \\
2(8.70 \%) \\
3(13.04 \%) \\
0(0 \%) \\
0(0 \%) \\
1(4.35 \%)\end{array}$ & 0.648 \\
\hline First needle prick time (weeks) & $6.44 \pm 2.38$ & $8.19 \pm 10.10$ & 0.303 \\
\hline Maturation rate (at 8 weeks)* & $41(93.2 \%)$ & $21(95.5 \%)$ & 0.999 \\
\hline $\begin{array}{l}\text { Intervention:* } \\
\text { Revision } \\
\text { Thrombectomy } \\
\text { Angioplasty/stenting }\end{array}$ & $\begin{array}{l}3(6.8 \%) \\
1(2.3 \%) \\
3(6.8 \%)\end{array}$ & $\begin{array}{l}0(0.0 \%) \\
0(0.0 \%) \\
1(4.3 \%)\end{array}$ & 0.566 \\
\hline
\end{tabular}

Fistula was considered 'matured,' if it has satisfactory flow and palpable vein after 6-8 weeks, as defined by rule of $6 \mathrm{~s}$ in KDOQI guidelines. Primary patency was time-duration from fistula creation to first intervention. Secondary/cumulative patency was the total duration fistula-remained patent, despite having multiple interventions.

Data were entered and analysed using SPSS version 22 . Quantitative variables were reported as mean \pm SD and/or medians (range) and categorical variables were presented with frequencies and percentages. Group differences were assessed by Independent t test/Mann-Whitney test or Chisquare/Fisher exact test. A p-value $<0.05$ was considered significant.

During the study duration, 74 patients had BTT-AVF, out of them $51(68.9 \%)$ were diabetic, while $23(31.08 \%)$ were non-diabetic patients. There was more proportion of female patients in diabetics (76.47\% vs. $43.48 \%$ ). Mean age (years) of the diabetic patients were higher compared to non-diabetics $(60.27 \pm 8.9$ vs. $43.78 \pm 17.41, p<0.00)$. BMI of diabetic patients was also higher compared to non-diabetics ((28.32 \pm 7.18 vs. $23.59 \pm 4.51, p=0.005)$. Other demographics and preoperative and intraoperative variables were comparable (Table I). No significant difference in overall complication rates between the two groups were noted $(p=0.838$, Table I). Although, diabetic patients experienced a trend towards more steal syndromes $(19.6 \%$ vs. $13.04 \%, p=0.743)$.

Seven diabetic and one non-diabetic patient was lost to follow-up at 8 weeks; hence, 44 diabetic and 22 non-diabetic patients were available and assessed for fistula maturation and patency. Access maturation rates were comparable (93.2\% vs. 95.5\%) between the two groups. At 6 months, a trend of lower patency rate was noted in diabetics $(64.7 \%$ vs. $87.0 \%)$. The patency rates at 12 and 24 months were $63.6 \%$ vs. $70.0 \%$ and $27.3 \%$ vs. $14.3 \%$, respectively.

Diabetic nephropathy is the most common cause of renal failure; and usually affects elder population. Most of the other conditions of renal failure affect the younger population. There are limited studies addressing the effects of 
diabetes on the outcomes of the BBT-AVF, specifically. Most of the studies focused increased AVF failure rate in diabetic patients undergoing radiocephalic AVFs. ${ }^{4}$ The present results are consistent with recently published studies, Fontseré et al. noted diabetics had worse patency rates than non-diabetic patients. ${ }^{5}$

The present results differ from other studies. Zouaghi et al. evaluated 126 AVFs for its patency and its determinant factors, $39.6 \%$ were diabetics in that cohort, only $18(14.3 \%)$ had BBT-AVF; diabetes did not come as a risk factor for poor patency. ${ }^{6}$

Higher frequency of steal syndrome in diabetics may also be due more elderly (having advance atherosclerosis) and female (having smaller vessel diameter) patients in this cohort. Limited patency in diabetics can be due to advance atherosclerosis and poor vessel remodeling, which is expected in these patients. Preoperative ultrasound was performed in most patients, but complete data for arterial assessment was not available. This was one of the limitations of this retrospective study, others being from a single-centre with limited number of patients. A prospective, multi-centre study with larger sample size can better improve these results.

This study showed that the diabetic and non-diabetic patients undergoing BBT-AVF were comparable in terms of perioperative complications and maturation rate. However, diabetics had more incidences of steal syndrome compared to non-diabetic patients. Short term patency rate was lower in diabetics compared to non-diabetics.

\section{ETHICAL APPROVAL:}

Ethical approval was obtained from the Institutional Review Board and Ethics Committee.

\section{PATIENTS' CONSENT:}

Informed consents were taken from all patients.
The authors declared no conflict of interest.

AUTHORS' CONTRIBUTION:

ZR: Study concept, data acquisition and analysis, manuscript writing, critical review, final approval.

WMS: Data acquisition, data analysis, critical review and final approval.

ASP: Data collection and final approval.

\section{REFERENCES}

1. Orlowski HLP, McWilliams S, Mellnick VM, Bhalla S, Lubner MG, Pickhardt PJ, et al. Imaging spectrum of invasive fungal and fungal-like infections. Radiographics 2017; 37(4): 1119-34. doi: 10.1148/rg.2017160110.

2. Conte MS, Nugent HM, Gaccione P, Roy-Chaudhury P. Influence of diabetes and perivascular allogeneic endothelial cell implants on arteriovenous fistula remodeling. J Vasc Surg 2011; 54(5): 1383-9. doi: 10.1016/j.jvs.2011.05.005.

3. Al-Isa AN, Thalib L, Akanji AO. Circulating markers if inflammation and endothelial dysfunction in Arab adolescent subjects: Reference ranges and association with age, gender, body mass and insulin sensitivity. Atherosclerosis 2010; 208(2):543-9. doi: 10.1016/j.atherosclerosis.2009. 07.056 .

4. Siddique MA, Ashraffs S, Carline T. Maturation of arteriovenous fistula: Analysis of key factors. Kidney Res Clin Pract 2017; 36(4): 318-328. doi: 10.23876/j.krcp.2017.36.4.318.

5. Fontseré $N$, Mestres $G$, Yugueros $X$, Jiménez $M$, Burrelc $M$, Gómezc $F$, et al. Brachiobasilic arteriovenous fistula with superficialisation and transposition the basilic vein in a onestage surgical technique. Five years of single experience. Fístulas arteriovenosas nativas humerobasílicas con superficialización y trasposición en un solo acto quirúrgico. Revisión de cinco años de experiencia. Nefrologia 2019; 39 (4):388-94. doi: 10.1016/j.nefro.2018.11.010.

6. Zouaghi MK, Lammouchi MA, Hassen M, Rais L, Krid M, Smaoui $W$, et al. Determinants of patency of arteriovenous fistula in hemodialysis patients. Saudi J kidney Dis Tranpl 2018; 29(3):615-22. doi: 10.4103/1319-2442.235183.

\section{CONFLICT OF INTEREST:}

